\title{
ELABORAÇÁO DE UMA FERRAMENTA DE AUTOAVALIAÇÁO DA SEGURANÇA VIÁRIA NO SETOR PÚBLICO MUNICIPAL
}

\author{
L. Ribeiro'; N. de Sousa²; J. T. Bastos ${ }^{3}$; B. P. S. Branco ${ }^{4}$ \\ 1,2.3,4 Universidade Federal do Paraná, Av. Coronel Francisco H. dos Santos, 100, Jd. das Américas. Curitiba/PR \\ ${ }^{4}$ Observatório Nacional de Segurança Viária, Rua Nove de Julho, 831, Vila Georgina. Indaiatuba, São Paulo. \\ ribeiroluana48@yahoo.com.br ${ }^{1}$,nati.gds@hotmail.com², jtbastos@ufpr.br ${ }^{3}$, beatriz.branco@onsv.org.br ${ }^{4}$
}

Resumo: Uma das principais mudanças trazidas pelo novo Código de Trânsito Brasileiro foi a atribuição ao município da responsabilidade sobre a gestão do trânsito. Isso significa que todos os municípios deveriam compor uma estrutura para realizar as atividades de engenharia, fiscalização e educação de trânsito. Com isso, o objetivo deste artigo é apresentar uma Ferramenta de Autoavaliação da Segurança Viária para o setor público municipal. A ferramenta proposta é formada por um conjunto de dez domínios: municipalização do trânsito, aderência à legislação urbanística, transporte não motorizado, monitoramento da segurança viária, controle de tráfego, gestão da velocidade, fiscalização, educação para o trânsito, sinalização de trânsito e regulamentaçôes adicionais. Cada domínio da ferramenta decompóe-se em subdomínios com métricas de avaliação da situação correspondente, que são: prática líder, prática intermediária, prática inicial e prática inexistente. A partir da avaliação de cada quesito tem-se um diagnóstico para o município, podendo ser utilizado como autoavaliação, bem como para o planejamento de açôes para a melhoria do processo de gestáo da segurança viária.

Palavras-chave: Gestão da segurança viária, Ferramenta de autoavaliação, Municipalização do trânsito.

\begin{abstract}
One of the main changes brought by the new Brazilian Traffic Code was the attribution of responsibilities about managing the city traffic. This means that every city should have a structure responsible of certain activities such as engineering, supervision and traffic education. Therefore, the objective of this paper is to introduce a tool of self-assessment of road safety to the public sector. The proposed tool is formed by a set of domains: traffic municipalization, adherence to the urbanistic legislation, non-motorized transport, road safety monitoring, traffic control, speed management, supervision, traffic education, traffic signaling and additional regulations. Each domain of the tool is composed by subdomains with metrics to evaluate the corresponding situation: leader practice, intermediate practice, initial practice and inexistent practice. The evaluation of each item results on a diagnosis for the city, which can be used as a self-evaluation, as well for planning some actions that would improve the road safety management process.
\end{abstract}

Keywords: Road safety management, Self-assessment tool, Traffic municipalization. 


\section{Introduçáo}

No contexto global, a gestáo da segurança no trânsito é indicada como um dos cinco pilares da Década Mundial de Ações para a Segurança Viária - estabelecida pela Organização das Nações Unidas (ONU) como o período que vai de 2011 a 2020 - necessários para que os países consigam atingir a meta de redução de 50\% do número de mortes no trânsito previsto para 2020 [1]. No cenário brasileiro, atingir a meta proposta pela ONU representa uma redução de 42.542 mortes em 2010 para 31.483 mortes em 2020 [2]. Entretanto, o que se observa é que as mortes no trânsito apresentam uma tendência de crescimento a partir do ano 2000, que pode ter decorrido após o então novo Código de Trânsito Brasileiro (CTB) ter entrado em vigor [3].

Entre os avanços trazidos pelo CTB de 1998 está a “municipalização do trânsito”, processo no qual o município passa a ser responsável integral, legal, administrativa e tecnicamente, pelos serviços de trânsito relativos à engenharia, fiscalização, educação de trânsito, levantamento e gestão de dados coletados [4]. Dessa maneira, a responsabilidade de garantir a circulação segura de pessoas e recursos está, sobretudo, no município. A municipalização se caracteriza então como passo inicial para a realização das tarefas de gestão da segurança viária e para contribuir no sentido de atingir a meta de redução do número de mortes.

Tendo em vista a relevância do tema e o baixo número de municípios integrados ao Sistema Nacional de Trânsito (SNT)[5], o presente trabalho oferece uma contribuição para que gestores do setor público municipal, possam avaliar as açóes municipais em termos de segurança viária. Entende-se que a realização de um diagnóstico é fundamental para a identificação tanto de boas práticas como de deficiências capazes de influenciar na situação da segurança viária no âmbito municipal.

\section{Metodologia}

\subsection{Concepçáo e construçáo da ferramenta}

Inicialmente foram determinados domínios da FASV, ou seja, os temas associados à gestão da segurança viária que a ferramenta deveria contemplar. A partir desta escolha, foi realizada a pesquisa bibliográfica sobre aspectos que poderiam ser relevantes para a ferramenta conforme cada tema. Com base no objetivo e no referencial teórico, partiu-se para a construção da ferramenta.

\subsubsection{Estrutura da ferramenta}

Os temas selecionados para avaliação dos municípios foram: municipalização do trânsito, aderência à legislação, transporte não motorizado, monitoramento/gestão da segurança viária, controle de tráfego, gestão da velocidade, fiscalização, educação para o trânsito e regulamentaçóes adicionais, os quais determinam os domínios que constituem a FASV. 
Cada domínio, por sua vez, é composto por diversos temas importantes para a realização de uma avaliação objetiva da gestão da segurança viária no município, que foram denominados de subdomínios. Para avaliar a situação relativa a cada subdomínio, foram estabelecidos quatro tipos de situaçôes: ausência da prática, prática inicial, prática intermediária e prática avançada. No exemplo da Figura 1, observam-se os subdomínios de um do domínio específico, que se repetem para cada tema, de acordo com o porte de cada município.

\begin{tabular}{|c|c|c|c|c|}
\hline \multicolumn{5}{|c|}{ MUNICIPALIZAÇÃO } \\
\hline & Ausência da prática & Prática inicial & Prática intermediária & Prática avançada \\
\hline $\begin{array}{c}\text { Processo de } \\
\text { integração ao SNT }\end{array}$ & $\begin{array}{l}\text { Não há nenhuma ação para iniciar o } \\
\text { processo de integração do município } \\
\text { ao SNT. }\end{array}$ & $\begin{array}{l}\text { O processo de municipalização já foi } \\
\text { inciado, porém há dificuldades em } \\
\text { algum elemento da estrutura } \\
\text { necessária. }\end{array}$ & $\begin{array}{l}\text { O processo de municipalização foi } \\
\text { concluido, porém há dificuldades na } \\
\text { prática das ações de engenharia, } \\
\text { fiscalização e educação para o } \\
\text { trânsito. }\end{array}$ & $\begin{array}{l}\text { O processo de municipalização já foi } \\
\text { plenamente concluído e há ações } \\
\text { efetivas de engenharia, fiscalização e } \\
\text { educação para o trânsito. }\end{array}$ \\
\hline Área de engenharia & \begin{tabular}{|l|} 
Não há nenhuma iniciativa em \\
relação à engenharia de trânsito.
\end{tabular} & $\begin{array}{|lr|}\text { Apesar da estrutura institucional } \\
\text { necessária, não há uma } & \text { equipe de } \\
\text { profissionais } & \text { de } \\
\text { engenharia/arquitetura responsáveis } \\
\text { pelo setor. }\end{array}$ & $\begin{array}{l}\text { Apesar da estrutura institucional } \\
\text { necessária, há uma equipe pouco } \\
\text { estruturada de profissionais de } \\
\text { engenharia/arquitetura responsáveis } \\
\text { pelo setor. }\end{array}$ & $\begin{array}{l}\text { Há uma equipe de profissionais } \\
\text { habilitados na área de engenharia } \\
\text { responsáveis pelos estudos e } \\
\text { intervenções na área. }\end{array}$ \\
\hline Área de fiscalização & $\begin{array}{l}\text { Não há nenhuma iniciativa em } \\
\text { relação à fiscalização de trânsito. }\end{array}$ & $\begin{array}{l}\text { Apesar da estrutura institucional } \\
\text { necessária, não há uma equipe de } \\
\text { agentes que atue constantemente em } \\
\text { atividades de fiscalização. }\end{array}$ & $\begin{array}{l}\text { Apesar da estrutura institucional } \\
\text { necessária e de uma equipe de } \\
\text { agentes, há dificuldades operacionais } \\
\text { que impedem o exercicio continuado } \\
\text { das atividades de fiscalização. }\end{array}$ & $\begin{array}{l}\text { Há uma equipe fixa de agentes que } \\
\text { garantem a realização continuada de } \\
\text { atividades de fiscalização de trânsito. }\end{array}$ \\
\hline Área de educação & $\begin{array}{l}\text { Não há nenhuma iniciativa em } \\
\text { relação à educação para o trânsito. }\end{array}$ & $\begin{array}{l}\text { Há ações isoladas desenvolvidas por } \\
\text { diferentes órgãos. }\end{array}$ & \begin{tabular}{|l|} 
Há ações continuadas de educação \\
para o trânsito de acordo com um \\
planejamento pré definido, apesar de \\
não haver uma Escola Pública de \\
Trânsito.
\end{tabular} & $\begin{array}{l}\text { Há ações continuadas de educação } \\
\text { para o trânsito de acordo com um } \\
\text { planejamento pré definido. Há uma } \\
\text { Escola Pública de Trânsito que } \\
\text { desempenha atividades de educação } \\
\text { para o trânsito voltadas para a } \\
\text { sociedade em geral. }\end{array}$ \\
\hline $\begin{array}{l}\text { Recursos das } \\
\text { multas }\end{array}$ & $\begin{array}{l}\text { Não há estrutura para arrecadação de } \\
\text { valores de multas. }\end{array}$ & $\begin{array}{l}\text { Apesar da criação da JARI, há } \\
\text { dificuldades no acesso ao recurso } \\
\text { das multas. }\end{array}$ & $\begin{array}{l}\text { Apesar da criação da JARI, há } \\
\text { dificuldades para aplicação dos } \\
\text { recursos de multas. }\end{array}$ & $\begin{array}{l}\text { Há uma JARI e os recursos das } \\
\text { multas são aplicados em projetos de } \\
\text { trânsito. }\end{array}$ \\
\hline
\end{tabular}

Figura 1 - Aplicação das réguas para Municipalização.

Fonte: Os autores (2016).

$\mathrm{Na}$ ferramenta, cada tema é apresentado com as alternativas das réguas como resposta. As réguas consistem na estrutura da FASV. Cada subdomínio é um tema a ser refletido e respondido e os níveis das réguas são as alternativas a serem assinaladas. Na Figura 2, a seguir, é apresentada a relação de todos os subdomínios avaliados. 


\begin{tabular}{|c|c|c|}
\hline & Subdomínios & Domínios \\
\hline 1 & Plano de transporte público integrado & \multirow{5}{*}{$\begin{array}{l}\text { LEGISLAÇÃO } \\
\text { URBANIISTICA }\end{array}$} \\
\hline 2 & Plano diretor & \\
\hline 3 & Plano de mobilidade & \\
\hline 4 & Compatibilização entre os planos & \\
\hline 5 & Plano de desenvolvimento urbano integrado & \\
\hline 6 & Processo de integração ao SNT & \multirow{5}{*}{$\begin{array}{c}\text { MUNICIPALIZAÇÃO } \\
\text { DO TRÂNSITO }\end{array}$} \\
\hline 7 & Área de engenharia & \\
\hline 8 & Área de fiscalização & \\
\hline 9 & Área de educação & \\
\hline 10 & Recursos das multas & \\
\hline 11 & Programa de manutenção e extensão de calçadas & \multirow{8}{*}{$\begin{array}{l}\text { TRANSPORTE NÃO } \\
\text { MOTORIZADO }\end{array}$} \\
\hline 12 & Programa de adequação de calçadas/meio fio para PNE & \\
\hline 13 & Condições da segurança pública que afetam a demanda & \\
\hline 14 & Planejamento cicloviário & \\
\hline 15 & Expansão da rede cicloviária & \\
\hline 16 & Extensão da rede cicloviária & \\
\hline 17 & Estacionamento para bicicletas & \\
\hline 18 & $\begin{array}{l}\text { Condições da segurança pública que afetam a } \\
\text { circulação de ciclistas }\end{array}$ & \\
\hline 19 & Estatística de acidentes & \multirow{2}{*}{ MONITORAMENTO } \\
\hline 20 & Planejamento e monitoramento das ações & \\
\hline 21 & Controle eletrônico de velocidade & \multirow{2}{*}{$\begin{array}{l}\text { GESTÃO DA } \\
\text { VELOCIDADE }\end{array}$} \\
\hline 22 & Medidas físicas de controle de velocidade & \\
\hline 23 & $\begin{array}{l}\text { Ações continuadas de educação para o trânsito } \\
\text { empreendidas em escolas municipais }\end{array}$ & \multirow{2}{*}{$\begin{array}{c}\text { EDUCAÇÃO PARA O } \\
\text { TRÂNSITO }\end{array}$} \\
\hline 24 & $\begin{array}{l}\text { Ações continuadas de educação voltadas para a } \\
\text { sociedade em geral }\end{array}$ & \\
\hline 25 & Gestão da sinalização & \multirow{3}{*}{$\begin{array}{l}\text { CONTROLE DE } \\
\text { TRÁFEGO }\end{array}$} \\
\hline 26 & $\begin{array}{l}\text { Estratégias de controle de tráfego (apenas placa, } \\
\text { semaforo e rotatória) }\end{array}$ & \\
\hline 27 & $\begin{array}{l}\text { Tecnologia no controle semafórico - coordenação } \\
\text { semafórica, controle de avanço do sinal e semáforos } \\
\text { atuados pelo tráfego }\end{array}$ & \\
\hline 28 & Número de agentes & \multirow{4}{*}{ FISCALIZAÇÃO } \\
\hline 29 & Programas de treinamento de agentes & \\
\hline 30 & Política de fiscalização & \\
\hline 31 & Dispositivos de fiscalização & \\
\hline 32 & Existência de regulamentações adicionais & \multirow{2}{*}{$\begin{array}{l}\text { REGULAMENTAÇÕES } \\
\text { ADICIONAIS }\end{array}$} \\
\hline 33 & Vistoria & \\
\hline
\end{tabular}

Figura 2 - Relação dos Subdomínios da FASV. Fonte: Os autores (2016).

Também foram definidos parâmetros para determinação de filtros para classificação de grupo. Estes parâmetros são: a população do município, o município faz parte ou não de Região Metropolitana, e o município está ou não integrado ao SNT.

Com relação à população do município, a aplicação da Ferramenta é divida em grupos, conforme: (1) menor que 20 mil habitantes (população para o qual é dispensado o Plano Diretor e o Plano de Mobilidade); (2) entre 20 mil e 500 mil habitantes; e (3) maior que 500 mil habitantes (população acima da qual é necessário que o município apresente um Plano Integrado de Transporte Público). 


\subsubsection{Ferramenta de aplicação}

A plataforma escolhida para iniciar a ferramenta foi o Google forms, que é um dispositivo gratuito e online para elaboração de questionários, e que apresentava os recursos necessários para a construção e aplicação da FASV, além da praticidade Além disso, outro motivo que levou a essa escolha foi a facilidade para disponibilizar a ferramenta aos municípios.

Após o usuário terminar de responder e enviar suas respostas, estas ficam armazenadas no próprio site do Google forms, em um campo de acesso exclusivo dos autores. Estas podem ser visualizadas individualmente em forma de questionário preenchido (para cada município respondente), ou coletivamente (todas as respostas) em forma de gráficos gerados pela própria plataforma. O Google forms mostrou-se uma plataforma bastante prática para aplicação do questionário.

\subsection{Validaçáo da ferramenta}

Após o processo de elaboração da FASV, sua aplicabilidade foi testada em três municípios. As cidades que colaboraram nesta etapa foram Curitiba/PR (grande porte), Sorocaba/SP (médio porte) e Tibagi/PR (pequeno porte). Houve contato com membros do corpo técnico do setor público municipal, os quais se dispuseram a colaborar com o trabalho. A principal preocupação era verificar se a FASV se adequava a municípios de diferentes portes. Dessa forma, foi solicitado que fossem realizadas avaliaçôes como: a adequação da ferramenta à realidade do município; a interpretação das réguas; se houve elementos importantes que não foram contemplados pela ferramenta; e sugestôes.

O retorno recebido foi principalmente em relação à linguagem técnica utilizada; à necessidade de conhecimentos de várias áreas para responder, necessitando de mais de um funcionário para poder responder às questóes; e à adequação a realidade de cada município, levando em consideração as características específicas e peculiaridades de cada um. Baseado no retorno dos municípios, foram realizados ajustes na FASV para melhoria e adequação às diferentes realidades, bem como alteraçóes na sequência lógica da ferramenta.

\section{Resultados}

Nos resultados serão abordadas a FASV final - após a validação realizada a partir de sugestôes de profissionais consultados -, e também o que a FASV pode gerar para o município - como um diagnóstico da situação atual em relação à segurança viária, por exemplo. 


\subsection{A ferramenta proposta}

A ferramenta foi disponibilizada em uma página da internet e é acessada através de um link que pode ser transmitido via e-mail. Ao acessar a página, o usuário se depara com a identificação da FASV e logo em seguida com um breve texto de instruçôes básicas. Após esse processo, o usuário inicia o preenchimento da ferramenta. Os primeiros dados solicitados são o e-mail do técnico responsável pelo preenchimento, e o nome do município. Na sequência, é questionada a população da cidade analisada e então o preenchimento de cada domínio e respectivos subdomínios.

Com a utilização da FASV, o município consegue analisar sua situação atual em relação à gestão da segurança viária municipal com o auxílio de um arquivo de diagnóstico gerado pela ferramenta. A geração deste diagnóstico ainda não ocorre de forma automatizada, pois depende do tratamento dos dados e envio dos resultados ao município por uma pessoa que entenda do assunto.

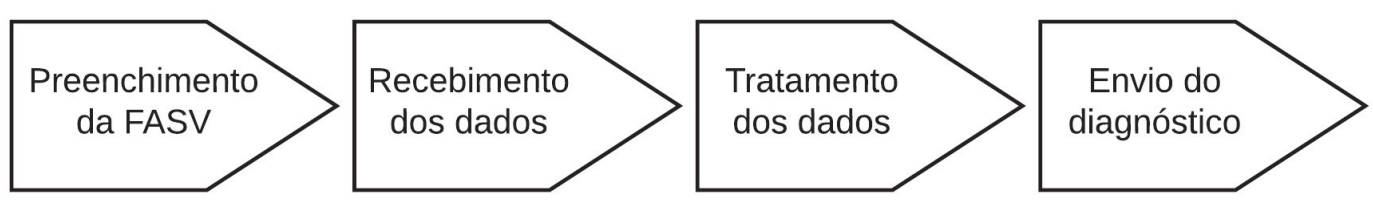

Figura 3 - Procedimento para obter o diagnóstico pela FASV. Fonte: Os autores (2017).

\subsection{Diagnóstico}

Conforme a definição da FASV, os cinco tipos de situações que podem ser encontradas em cada subdomínio são: não apto a responder ou não se aplica; ausência da prática; prática inicial; prática intermediária; e prática avançada. Para cada uma dessas situaçóes foi definida uma porcentagem de desempenho. Na Figura 4, o desempenho para cada subdomínio é apresentado em escala de cores e porcentagem.

\begin{tabular}{|ccccc|}
\hline Não se aplica & Ausência de prática & Pratica inicial & Prática intermediária & Prática avançada \\
- & $0 \%$ & $33 \%$ & $67 \%$ & $100 \%$ \\
\hline
\end{tabular}

Figura 4 - Desempenho para cada Subdomínio. Fonte: Os autores (2016).

O diagnóstico permite observar de um modo geral a situação do município. Para tal, calcula-se o desempenho médio dos subdomínios pertencentes a cada domínio.

Para os exemplos a seguir, parte-se da hipótese de um município, com população superior a 500 mil habitantes, pertencente à região metropolitana e que possui seu trânsito municipalizado. 
3.2.1 Exemplo de aplicação - Desempenho de cada subdomínio

A análise de desempenho do município pode ser observada com um gráfico de barras dos subdomínios referentes a cada domínio pertencente, oferecendo uma fácil leitura do desempenho. $\mathrm{Na}$ Figura 5, têm-se o domínio da Legislação Urbanística para ilustrar o exemplo considerado. Para cada subdomínio existe uma prática selecionada de acordo com a realidade do município. Complementarmente, para cada prática, está associada uma porcentagem do seu desempenho, como pode ser observado na Figura 6.

Instrumentos da legislação urbanística

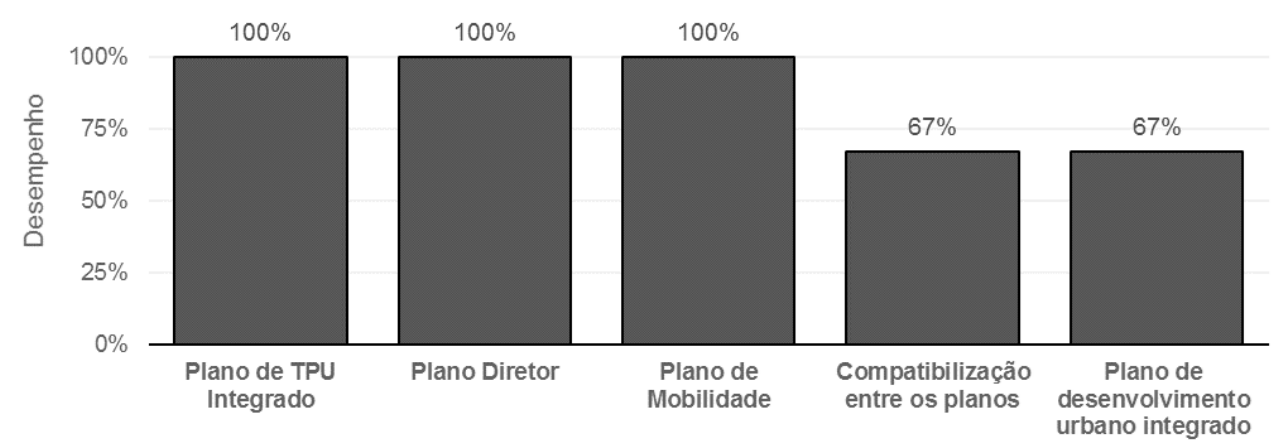

Figura 5 - Gráfico de desempenho dos Subdomínios dos Instrumentos da Legislação Urbanística. Fonte: Os autores (2016).

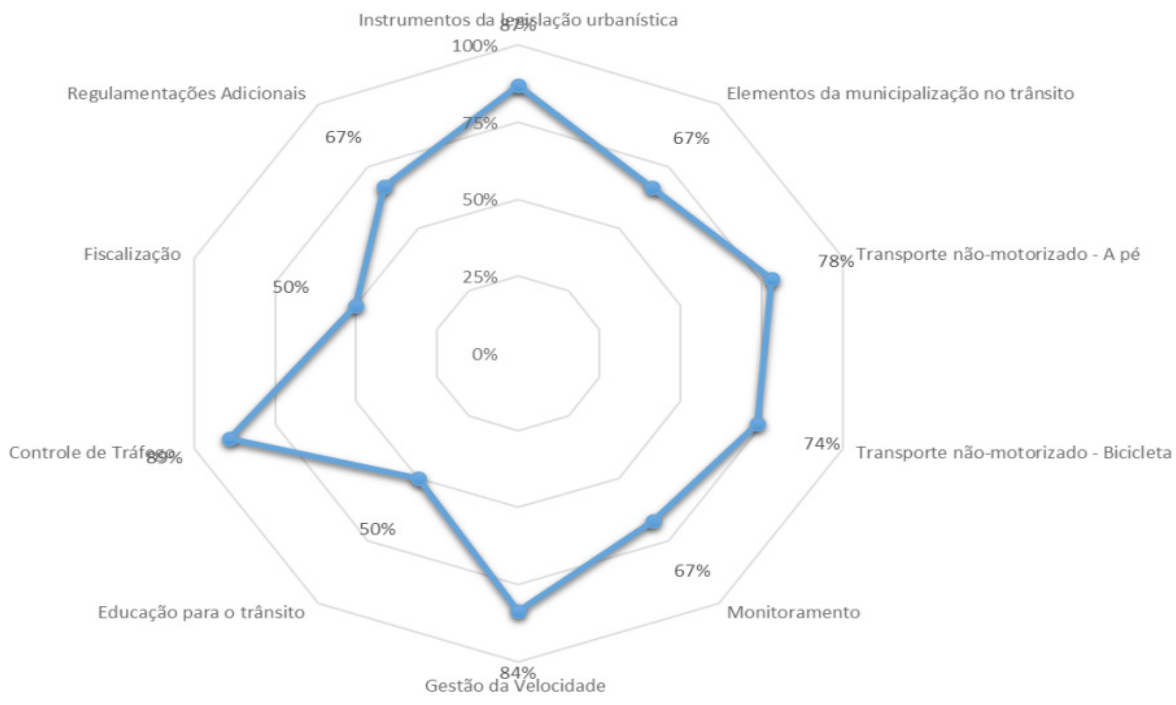

Figura 6 - Gráfico de avaliação geral do desempenho médio dos Domínios. Fonte: Os autores (2016). 
3.2.2 Exemplo de aplicação - Tabela de Desempenho

A Tabela de Desempenho é uma classificação do desempenho de modo geral avaliado subdomínio a subdomínio. É utilizada uma escala de cores com o mesmo critério apresentado na Figura 6. Na Figura 7, pode-se observar um exemplo de Tabela de Desempenho.

Em resumo, apresenta o desempenho conjunto de todos os domínios e seus subdomínios por meio de uma visualização bastante clara dos pontos fracos e fortes, assim podendo se ter uma base para montar uma estratégia para melhorar a gestão da segurança viária do município - plano de açóes.

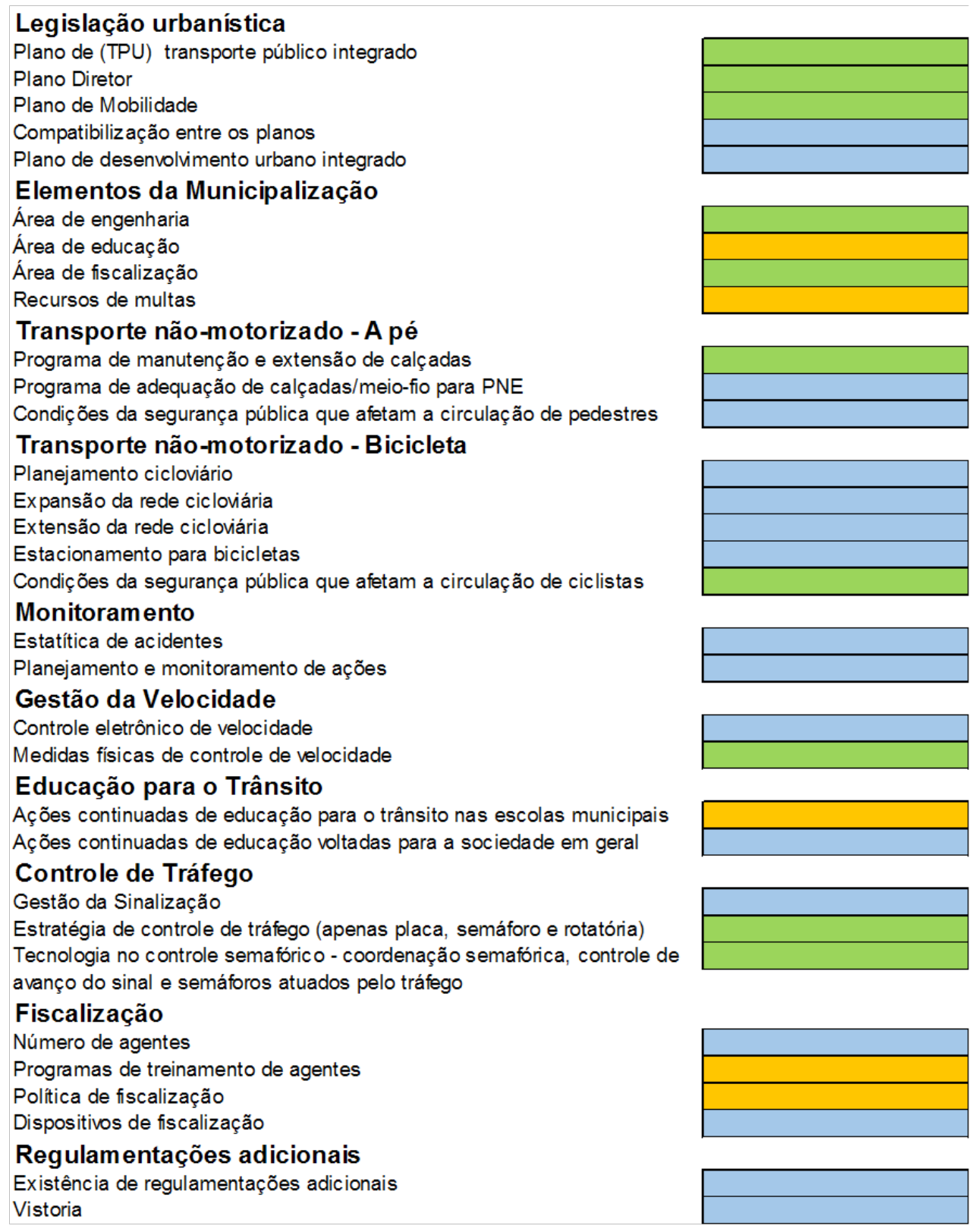

Figura 7 - Diagnóstico: Tabela de Desempenho.

Fonte: Os autores (2016). 


\section{Conclusóes}

A elaboração da FASV consistiu em um passo inicial para a disponibilização mais ampla de uma forma de diagnóstico para os municípios brasileiros. No entanto, ainda há muito espaço para aprimoramentos, principalmente no sentido da automatização dos processos de geração e envio do arquivo de diagnóstico.

Em um momento futuro, após uma amostra razoável de municípios já terem respondido à ferramenta, análises comparativas entre municípios podem ser realizadas, por exemplo, no sentido de associar o desempenho dos municípios nos diferentes domínios e as taxas de acidentalidade/mortalidade no trânsito, o nível de renda, nível de desenvolvimento humano, entre outros indicadores que influenciam na situação da segurança viária.

\section{Referências}

[1] ORGANIZAÇÃO MUNDIAL DA SAÚDE - OMS. Plano Global para a Década de Açáo para Segurança Viária 2011 - 2020. 2011, Suíça. Disponível em: <http://www.who.int/roadsafety/decade_of_action/plan/plan_ english.pdf?ua=1>. Acesso em: 15 dez. 2017.

[2] BASTOS, J. T., BERNARDINIS, M. A. P., BUHER, B. M. C., JÚNIOR, P. R. G.. Uma retrospectiva acerca do desempenho brasileiro no contexto da década mundial de açóes para a segurança viária. In: XXX ANPET, 2016, Rio de Janeiro. Caderno do Congressita.

[3] CÓDIGO DE TRÂNSITO BRASILEIRO - CTB - LEI No 9.503, de 23 de setembro de 1997.

[4] MINISTÉRIO DAS CIDADES. Pacto para reduzir acidentes de trânsito é assinado no Ministério das Cidades. 2011, Brasília. Disponível em: <https://www.cidades.gov.br/ultimas-noticias/1006-pacto-para-reduziracidentes-de-transito-e-assinado-no-ministerio-das-cidades>. Acesso em: 16 nov. 2017.

[5] MINISTÉRIO DAS CIDADES. Serviço de Informaçáo ao Cidadáo - SIC. Disponível em: <http://www. consultaesic.cgu.gov.br/busca/dados/Lists/Pedido/Item/displayifs.aspx?List=0c839f31-47d7-4485-ab65-ab0cee9cf8fe\& ID=466537\&Content TypeId=0x0100AE261DF45E46AD47A7DEBCBDF8776B88>. Acesso em: 28 set 2017. 